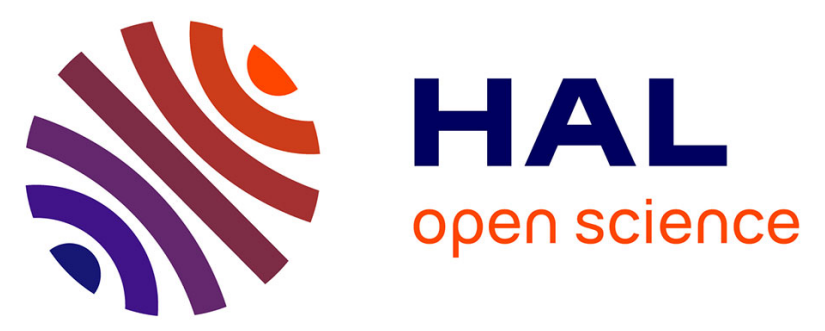

\title{
Triplet state CPL active helicene-dithiolene platinum bipyridine complexes
}

Thomas Biet, Thomas Cauchy, Qinchao Sun, Jie Ding, Andreas Hauser, Patric Oulevey, Thomas Bürgi, Denis Jacquemin, Nicolas Vanthuyne, Jeanne

Crassous, et al.

\section{To cite this version:}

Thomas Biet, Thomas Cauchy, Qinchao Sun, Jie Ding, Andreas Hauser, et al.. Triplet state CPL active helicene-dithiolene platinum bipyridine complexes. Chemical Communications, 2017, 53 (66), pp.9210-9213. 10.1039/c7cc05198k . hal-01579651

\section{HAL Id: hal-01579651 https://hal-univ-rennes1.archives-ouvertes.fr/hal-01579651}

Submitted on 29 Mar 2018

HAL is a multi-disciplinary open access archive for the deposit and dissemination of scientific research documents, whether they are published or not. The documents may come from teaching and research institutions in France or abroad, or from public or private research centers.
L'archive ouverte pluridisciplinaire HAL, est destinée au dépôt et à la diffusion de documents scientifiques de niveau recherche, publiés ou non, émanant des établissements d'enseignement et de recherche français ou étrangers, des laboratoires publics ou privés. 


\title{
Triplet state CPL active helicene-dithiolene platinum bipyridine complexes
}

\author{
Thomas Biet, ${ }^{\mathrm{a}}$ Thomas Cauchy, ${ }^{\mathrm{a}}$ Qinchao Sun, ${ }^{\mathrm{b}}$ Jie Ding, ${ }^{\mathrm{b}}$ Andreas Hauser, ${ }^{* \mathrm{~b}}$ Patric \\ Oulevey, ${ }^{\mathrm{b}}$ Thomas Bürgi, ${ }^{\mathrm{b}}$ Denis Jacquemin, ${ }^{\mathrm{c}}$ Nicolas Vanthuyne, ${ }^{\mathrm{d}}$ Jeanne Crassous ${ }^{\mathrm{e}}$ \\ and Narcis Avarvari*a
}

\begin{abstract}
Chiral metal dithiolene complexes represent a family of chiral precursors, which can give rise to molecular materials with properties resulting from the interplay of chirality with conductivity, magnetism, and photophysics. We describe herein the first examples of chiral metal diimine dithiolene complexes, by the use of a platinum(II) centre coordinated by 2,2'-bipyridine and helicene-dithiolene ligands. Straightforward synthesis of racemic and enantiopure complexes allows the preparation of luminescent $\operatorname{Pt}($ bipy) [4] and [6]helicene compounds for which the solid-state structure was determined as well. TD-DFT calculations support the assignment of the low energy bands observed in the UV-vis absorption spectra as mixed metal-ligand-to-ligand charge transfer transitions and confirm that the emission band results from the $T_{1}$ excited state. Interestingly the enantiopure [6] helicene complexes show CPL activity at room temperature in acetonitrile solutions with anisotropy factors of $3 \times 10^{-4}$.
\end{abstract}

Chiral metal dithiolene complexes represent an emerging family of molecular materials where chirality is expected to modulate properties such as conductivity, magnetism, luminescence, etc. ${ }^{1}$ For example, differences in conductivity between diastereomeric pairs of anionic $\mathrm{Ni}$ (II) bis(dithiolene) complexes with chiral viologene type cations have been noticed, ${ }^{2}$ while the first chiral single component conductors based on neutral $\mathrm{Au}(\mathrm{III})$ bis(dithiolene) complexes have been recently described. ${ }^{3}$ Besides, stable anionic, neutral or cationic species can be easily accessed in metal bis(dithiolene) complexes thanks to the "non-innocent" character of the dithiolene ligands, so that redox modulation of the chiroptical properties can be observed. ${ }^{4}$ Although square planar platinum diimine dithiolene complexes have been investigated over more than twenty years especially for their emission properties in solution, ${ }^{5-8}$ and more recently for photocatalytic water splitting, ${ }^{9}$ no chiral derivative of this heteroleptic family has been yet reported. For example, in $\mathrm{Pt}(\mathrm{II})$ 2,2'-bipyridine (bpy) arene-dithiolene complexes such as $\mathrm{Pt}(\mathrm{bpy})(\mathrm{tdt})(\mathrm{tdt}=$ toluenedithiolate) showing room temperature luminescence in solution arising from a MMLL'CT (mixed metal-ligand-to-ligand charge transfer) transition, ${ }^{5,6}$ chirality could be in principle introduced either on the diimine or the benzodithiolene fragments in order to influence the photophysical properties. One of the interests of such complexes relies on the possible observation of circularly polarized luminescence (CPL), which is the differential spontaneous emission of left and right-handed circularly polarized light. ${ }^{10}$ While chiral lanthanide complexes are generally the most intense CPL emitters, ${ }^{11,12}$ several examples of transition metal complexes have been reported as well. ${ }^{13-15}$ Among them those containing helicene based ligands are particularly interesting, ${ }^{16,17}$ as helicenes ${ }^{18,19}$ and heterohelicenes ${ }^{20}$ are well known non-planar conjugated molecules possessing strong chiroptical properties. Note that CPL active cationic dioxa, azaoxa and diaza [6] helicenes have been recently reported. ${ }^{21}$ This work is presenting out investigations on helical dithiolene platinum 2,2'-bipyridine complexes using the hitherto unknown helicene-dithiolate (heldt) ligands, by analogy with the achiral toluene-dithiolate (tdt) previously mentioned. We describe herein the synthesis and the structural characterization of $\mathrm{Pt}(\mathrm{bpy})([\mathrm{n}]$ hel-dt $)(\mathrm{n}=4,6)$ complexes together with their chiroptical and photophysical properties supported by DFT calculations.

The racemic 2,3-dithiolate-[4] and [6]helicene ligands, generated in situ from the protected precursors ( $r a c)-\mathbf{1 a}$ and (rac)-1b respectively, which have recently been used by some of us for the synthesis of TTF-helicenes, ${ }^{22}$ have been reacted with $\mathrm{Pt}(\mathrm{bpy}) \mathrm{Cl}_{2}$ to generate the corresponding complexes. Thus, (rac)-Pt(bpy)([4]hel-dt) 2a and (rac)-Pt(bpy)([6]hel-dt) 2b have been isolated as dark purple crystalline solids after column chromatography (Scheme 1 and ESI).

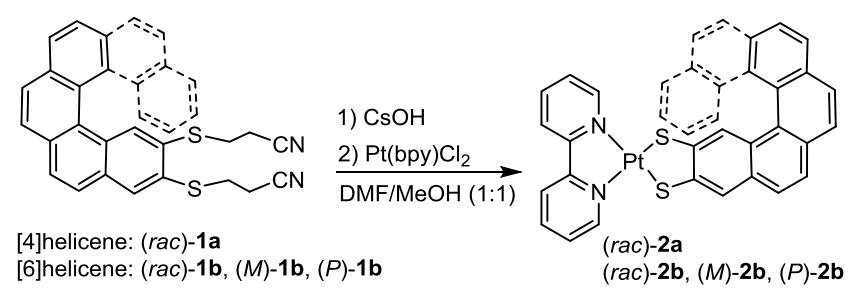

Scheme 1 Synthesis of Pt(bpy)(hel-dt) complexes 2a-b

As the racemization barrier for [4] helicenes is generally very low, ${ }^{23}$ the enantiopure forms have been prepared only for the [6]helicene dithiolene complexes $\mathbf{2 b}$ starting from the precursors $(M)$-1b and $(P)-\mathbf{1 b}$ separated by chiral HPLC (Fig. $\mathrm{S} 1-\mathrm{S} 3, \mathrm{ESI})$. The racemic complexes $\mathbf{2 a}$ and $\mathbf{2 b}$ crystallize in the centrosymmetric space groups $C 2 / \mathrm{c}$ and $P-1$ respectively, with both enantiomers $(M)$ and $(P)$ in the unit cell (Table $\mathrm{S} 1$, ESI). Worth noting are the helical curvatures (hc) defined by the dihedral angle between the terminal rings of the helicene skeleton amounting to $25.40^{\circ}$ and $53.76^{\circ}$ for $(\mathrm{rac}$ )-2a (Table S2, Fig. S4-S5, ESI) and (rac)-2b (Table S3, Fig. S6-S7, ESI), which are typical values for [4] and [6]helicenes, and the square planar coordination geometry of the platinum centres. DFT calculations in acetonitrile yield dihedral angles $28.06^{\circ}$ and $41.68^{\circ}$ for $\mathbf{2 a}$ and $\mathbf{2 b}$, suggesting that the impact of crystal packing is stronger for the latter compound. The enantiomerically pure complex $(M)$-2b has been also analysed by single crystal X-ray diffraction thus allowing to confirm that it was obtained from the (-)-1b precursor. $(M)-\mathbf{2 b}$ crystallized 
in the orthorhombic system, non-centrosymmetric space group $P 2{ }_{1}{ }_{1} 2{ }_{1}$, with four independent molecules in the unit cell (Fig. 1).

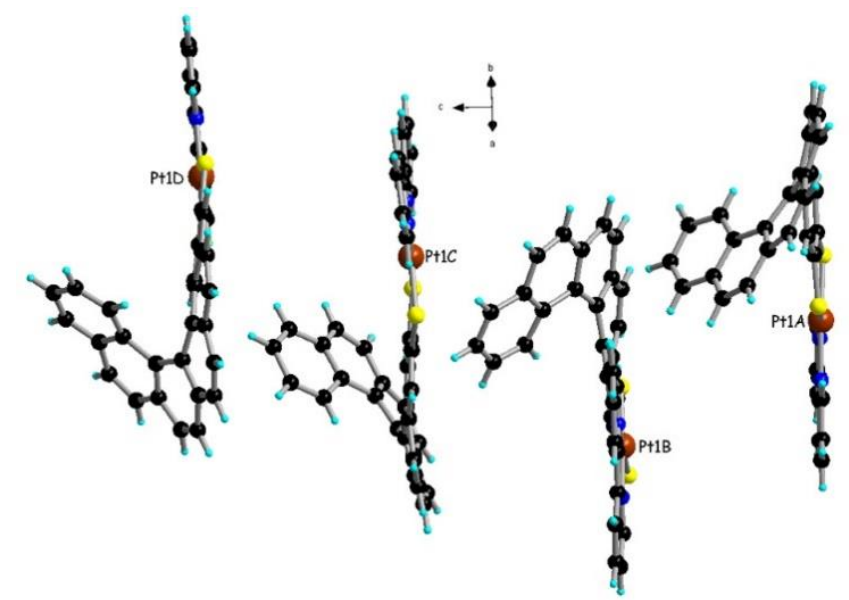

Fig. 1 The four independent molecules of complex in the solid state structure of (M)-2b.

The four molecules named as Pt1A - Pt1D slightly differ by the helical curvature values ranging from $58.58^{\circ}(\mathrm{Pt} 1 \mathrm{C})$ to $62.36^{\circ}$ (Pt1D), while the Pt-S (2.24-2.25 $\AA$ ) and Pt-N (2.05-2.07 $⿱$ A) are in the normal range for such complexes (Table S4, ESI). ${ }^{24}$ The packing of the molecules is very likely governed by the $\pi-\pi$ stacking interactions occurring along the $c$ direction (Fig. 1 and Fig. S8-S9, ESI).

The enantiomeric $(P)$ and $(M)$-2b complexes represent the first chiral members of the platinum diimine dithiolenes family. As outlined above, $\mathrm{Pt}$ (diimine)(dithiolate) complexes are emissive in fluid or frozen solutions. ${ }^{5,6,25}$ We have therefore set out to measure in a first time the photophysical properties of the racemic $\mathbf{2 a}$ and $\mathbf{2 b}$. In the low energy region the complex (rac)2a has an absorption band from 450 to $650 \mathrm{~nm}$ with a maximum around $550 \mathrm{~nm}\left(18180 \mathrm{~cm}^{-1}\right)$ and an absorption coefficient $\varepsilon \approx 6700 \mathrm{M}^{-1} \mathrm{~cm}^{-1}$ (Fig. 2, top). For (rac)-2b the maximum of the corresponding band is around $562 \mathrm{~nm}$ and the absorption coefficient $\varepsilon \approx 3640 \mathrm{M}^{-1} \mathrm{~cm}^{-1}$ (Fig. 2, bottom). This low energy absorption band is typical for $\mathrm{Pt}$ (diimine)(dithiolate) complexes and has been assigned to a MMLL'CT transition, as the HOMO has metal/dithiolene character while the LUMO is developed over the unsaturated diimine ligand. ${ }^{6}$ The small redshift of the CT transition from $\mathbf{2 a}$ to $\mathbf{2 b}$ is caused by the slight change in the dithiolate ligand, with a more extended rigid $\pi$ backbone in the latter, which makes the HOMO energy slightly higher by $+0.03 \mathrm{eV}$ in $\mathbf{2 b}$ than in 2a. Moreover, the absorption coefficient is smaller for 2b likely because of the more distorted structure. TD-DFT reproduces the experimental trends with a vertical absorption at $556 \mathrm{~nm}(\mathrm{f}=0.21)$ for $\mathbf{2 a}$ and $562 \mathrm{~nm}(\mathrm{f}=0.19)$ for $\mathbf{2 b}$. Both complexes are emissive in fluid solutions of $\mathrm{CH}_{2} \mathrm{Cl}_{2}$ when irradiated into the CT bands, showing low energy emission bands at $720 \mathrm{~nm}(\mathbf{2 a})$ and $715 \mathrm{~nm}$ (2b) (Fig. 2 and Fig. S10, ESI, for $(r a c)-2 a$ in $\left.\mathrm{CH}_{3} \mathrm{CN}\right)$. The more distorted structure of $\mathbf{2 b}$ might be as well at the origin of the lower emission quantum yield for $\mathbf{2 b}(0.15 \%)$ than for $\mathbf{2 a}(0.19 \%)$ (Table S5, ESI). The perfect agreement between absorption and excitation spectra is proof that the luminescence indeed originates from the two compounds despite the low emission quantum yield. For $\mathbf{2 b}$ a luminescence life-time of 124 ns was measured in deoxygenated solution with pulsed excitation at $458 \mathrm{~nm}$ (decay curve shown in Figure S11, ESI). With the quantum efficiency of $0.15 \%$ this corresponds to a radiative lifetime of around 100 $\mu \mathrm{s}$, indicating that the emission originates from the $\mathrm{T} 1 \mathrm{state}$, as is generally the case for $\mathrm{Pt}(\mathrm{II})$ complexes. ${ }^{6}$

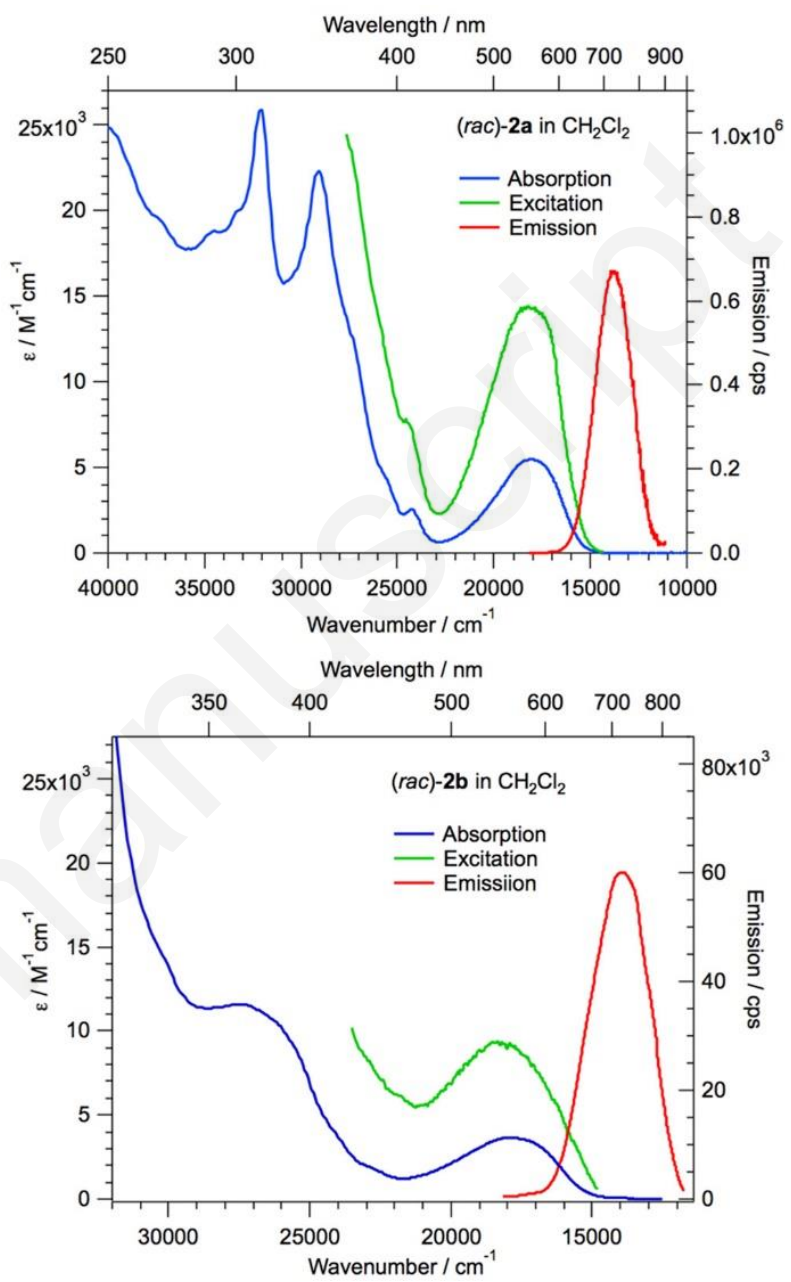

Fig. 2 Absorption, emission and excitation spectra of ( $r a c)-2 \mathbf{a}$ (top) and ( $\mathrm{rac}$ )-2b (bottom) in $\mathrm{CH}_{2} \mathrm{Cl}_{2}$. Absorption spectra were measured at concentrations of $2.2 \times 10^{-5} \mathrm{M}$ for $(\mathrm{rac})-2 \mathrm{a}$ and at $8 \times 10^{-5} \mathrm{M}$ for $(\mathrm{rac})-\mathbf{2 b}$. Emission spectra were measured using the same solutions degassed by nitrogen bubbling for $20 \mathrm{~min}$ with excitation at $525 \mathrm{~nm}$ for ( $\mathrm{rac}$ )-2a and at $560 \mathrm{~nm}$ for ( $\mathrm{rac}$ )-2b. Excitation spectra were measured at emission wavelengths of $720 \mathrm{~nm}$ for ( $\mathrm{rac}$ )-2a and 715 $\mathrm{nm}$ for $(r a c)-\mathbf{2 b}$.

To characterize the charge transfer and emission properties, DFT calculations have been performed on $\mathbf{2 a}$ and $\mathbf{2 b}$ (Fig. S12S19, Tables S6-S8, ESI). For both compounds, optimized as $(M)$ and $(P)$ enantiomers respectively, the fully relaxed molecular geometries obtained by DFT are in line with those obtained by X-Ray diffraction. In Fig. 3, we represent the electron density difference (EDD) plots corresponding to the transition to the lowest singlet excited-state and the spin density of the lowest emissive triplet state. The EDD representation clearly shows that there is a strong CT from the dithiolene (donor, mostly in blue in Fig. 3) to the diimine (acceptor, mostly in red). The computed CT distance attains $4.0 \AA$ in both $\mathbf{2 a}$ and $\mathbf{2 b}$, which is a rather large value. Interestingly, one notices that the metal centre presents both positive and negative 
density contributions, indicating that it also partially plays the role of an accepting unit. The implication of the metal in the EDD plots is also consistent with a possible intersystem crossing to the T1 state. The spin density of the lowest triplet state is unsurprisingly localized in exactly the same regions as the corresponding S1 state. The emission for the lowest triplet state was estimated in both the vertical and adiabatic approximations. In the former, DFT yields an emission at 802 $\mathrm{nm}$ and $815 \mathrm{~nm}$ for $\mathbf{2 a}$ and $\mathbf{2 b}$, respectively, whereas in the latter that takes into account the difference of vibrational energies, we obtained $759 \mathrm{~nm}$ and $760 \mathrm{~nm}$, for the two compounds. These latter values are in good correspondence with the experimental data, with an error smaller than $0.1 \mathrm{eV}$, confirming that the observed emission is indeed coming from T1. The fact that the vertical values indicate (incorrectly) a small redshift when going from $\mathbf{2 a}$ to $\mathbf{2 b}$, whereas the adiabatic energies show essentially no shift, hints that the $\mathrm{T}_{1}$ geometrical relaxation is smaller in the latter compound than in the former.
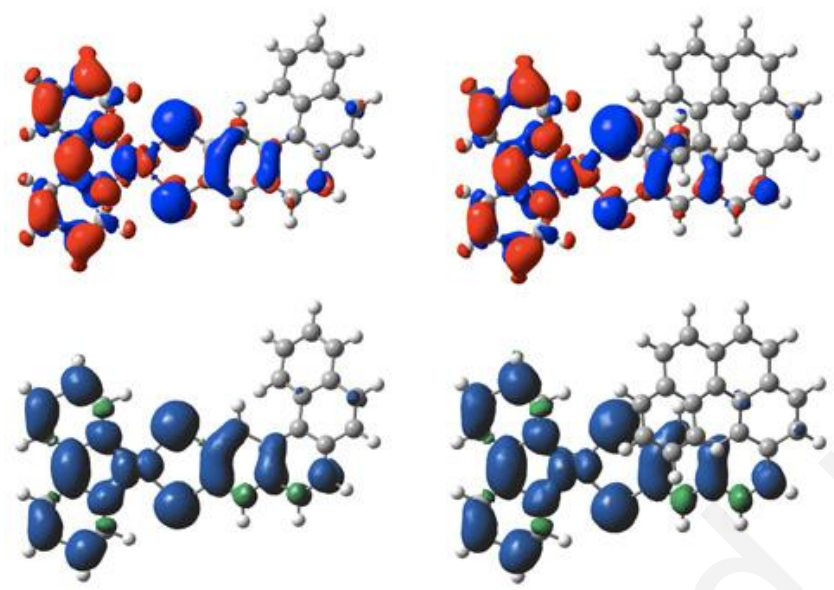

Fig. 3 Top: Density difference plots between the lowest $S_{1}$ and the $S_{0}$ state as determined by the TD-DFT on the optimal ground-state geometry. The blue (red) regions indicate regions of loss (gain) of density upon transition. Bottom: spindensity difference plots between the $T_{1}$ and $S_{0}$ states considering the $T_{1}$ state in its optimal geometry. $(M)-\mathbf{2} \mathbf{a}$ and $(P)-\mathbf{2} \mathbf{b}$ are displayed on the left and right handside, respectively. See the SI for computational details.

Investigation of the photophysical properties of both enantiomers of $\mathbf{2 b}$ has been performed in acetonitrile solutions. Absorption spectra are shown in the top panel of Fig. 4, together with the emission spectrum of $(M)-\mathbf{2 b}$. Compared to the spectra in $\mathrm{CH}_{2} \mathrm{Cl}_{2}$, the maximum of the absorption is shifted to $530 \mathrm{~nm}$, that is, by $30 \mathrm{~nm}$ to lower wavelength. The emission maximum in acetonitrile appears at $720 \mathrm{~nm}$, that is, shifted to higher wavelength by $5 \mathrm{~nm}$. The CD spectra of $(P)$ and $(M)-\mathbf{2 b}$ in acetonitrile, image mirror of each other, are shown in the bottom panel of Fig. 4. For the CD spectra, TD-DFT indeed yields a weakly positive contribution to the rotary strength for the transition to the lowest excited-state of $(P)-\mathbf{2 b}$ and a weakly negative contribution to that strength for the lowest excitedstate of $(M)-\mathbf{2 b}$, which is consistent with the experimental findings.

CPL, representing the differential emission between left and right circularly polarized light and characterized by the anisotropy factor $g_{e m}=2\left(I_{L}-I_{R}\right) /\left(I_{L}+I_{R}\right)$ at the maximum of the emission band, has been measured for solutions of $(M)$ and $(P)-\mathbf{2 b}$ in acetonitrile at room temperature (Fig. 4, bottom). As hypothesized through the introduction of the helicene backbone in the dithiolene ligand, the enantiomers of $\mathbf{2 b}$ show CPL activity with an anisotropy factor of $\pm 3 \times 10^{-4}$, which is a typical value for organic, organometallic and coordination complexes in solution excepting the lanthanides. ${ }^{11,12}$ It should be mentioned however that this value of CPL anisotropy is for a compound with a luminescence quantum efficiency of only $0.15 \%$, and which represents the first CPL active metal dithiolene complex.

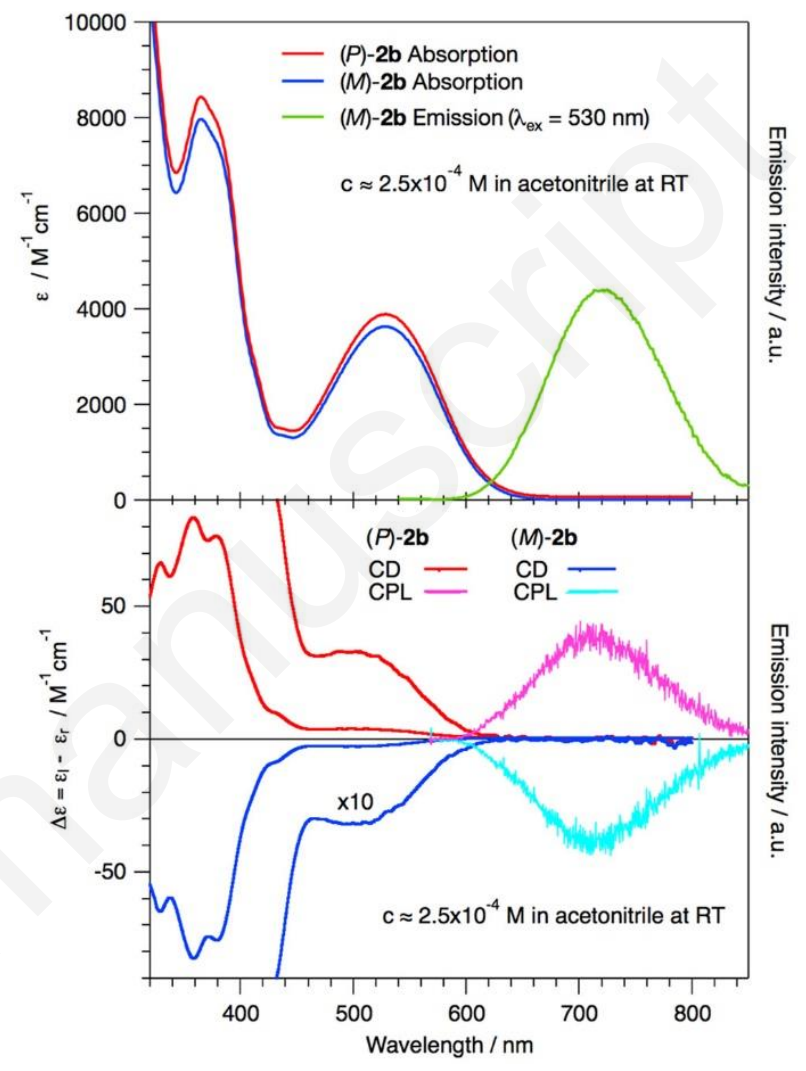

Fig. 4 Absorption spectra of $(P)-\mathbf{2} \mathbf{b}$ and $(M)-\mathbf{2} \mathbf{b}$ and emission spectrum of $(M)-\mathbf{2 b}$ in acetonitrile $\left(2.5 \times 10^{-4} \mathrm{M}\right)$ at $\mathrm{T}=298 \mathrm{~K}, \lambda_{\mathrm{ex}}=532 \mathrm{~nm}$ (top); $\mathrm{CD}$ and $\mathrm{CPL}$ spectra of $(P)-\mathbf{2} \mathbf{b}$ and $(M)-\mathbf{2} \mathbf{b}$ (bottom).

In summary, the first helical Pt(diimine)(dithiolene) complexes have been prepared through the introduction of [4] and [6]helicene backbones in the structures of the dithiolene ligand. The solid state structures of the racemic complexes show the presence of both $(P)$ and $(M)$ enantiomers, with helical curvatures typical of [4] and [6]helicenes and packings controlled by $\pi$ interactions. Enantiopure [6] helicene complexes have been prepared from the corresponding enantiopure precursors separated by chiral HPLC. The complexes are emissive in fluid solutions at room temperature when excited in the MMLL'CT band, the triplet state being responsible for the observed emission band centered at 715-720 nm. DFT calculations support the absorption, emission and CD properties of the enantiopure compounds. The conformationally stable [6]helicene enantiopure complexes show CPL activity. These results underline the interest of helical dithiolene ligands as means to access chirality related combined properties in the derived complexes and open the way towards the preparation of other related compounds by the use of chiral bipyridines in combination with diverse helicene-dithiolenes in order to tune their photophysical properties. 
This work was supported in France by the CNRS (GDR 3712 Chirafun), the University of Angers and the French Ministry of Education and Research (grant to T.B.). The investigation was supported in part by the University of Geneva and by the Swiss National Science foundation (grant No 200020_152780). Magali Allain (University of Angers) is warmly thanked for help with the solid state structures.

\section{Notes and references}

${ }^{a}$ Laboratoire Moltech-Anjou, Université d'Angers, CNRS UMR 6200, 2 bd Lavoisier, 49045 Angers, France. E-mail: narcis.avarvari@univangers.fr

${ }^{b}$ Department of Physical Chemistry, University of Geneva, 30 Quai Ernest Ansermet, CH-1211 Geneva, Switzerland. E-mail: Andreas.Hauser@unige.ch

${ }^{c}$ Laboratoire CEISAM, UMR CNRS 6230, Université de Nantes, 2 Rue de la Houssinière, BP 92208, 44322 Nantes Cedex 3, France and Institut Universitaire de France, 1 rue Descartes, 75005 Paris Cedex 5, France

${ }^{d}$ Aix Marseille Université, CNRS, Centrale Marseille, iSm2, Marseille, France

e Institut des Sciences Chimiques de Rennes, UMR 6226, CNRSUniversité de Rennes 1, Campus de Beaulieu, 35042 Rennes Cedex, France

Electronic Supplementary Information (ESI) available. Experimental details and characterization of compounds, X-ray data, CV, UV-vis, ECD, photophysical measurements and theoreti-cal calculations details (PDF).

CCDC 1550054 ((rac)-2a), 1550055 ((rac)-2b), 1550056 ((M)-2b) contain the supplementary crystallographic data (cif files) for this paper. See DOI: $10.1039 / \mathrm{c} 000000 \mathrm{x} /$

1 F. Pop and N. Avarvari, Coord. Chem. Rev., 2017, 346, 20-31.

2 H. Kisch, B. Eisen, R. Dinnebier, K. Shankland, W. I. F. David and F. Knoch, Chem. Eur. J., 2001, 7, 738-748.

3 D. G. Branzea, F. Pop, P. Auban-Senzier, R. Clérac, P. Alemany, E. Canadell and N. Avarvari, J. Am. Chem. Soc., 2016, 138, 6838-6851.

4 Y. Le Gal, A. Vacher, V. Dorcet, M. Fourmigué, J. Crassous and D. Lorcy, New J. Chem., 2015, 39, 122-129.

5 S. D. Cummings and R. Eisenberg, J. Am. Chem. Soc., 1996, 118, 1949-1960.

6 W. Paw, S. D. Cummings, M. A. Mansour, W. B. Connick, D. K. Geiger and R. Eisenberg, Coord. Chem. Rev., 1998, 171, 125-150.

7 T. Lazarides, T. M. McCormick, K. C. Wilson, S. Lee, D. W. McCamant and R. Eisenberg, J. Am. Chem. Soc., 2011, 133, 350364.

8 A. Pintus, M. C. Aragoni, N. Bellec, F. A. Devillanova, D. Lorcy, F. Isaia, V. Lippolis, R. A. M. Randall, T. Roisnel, A. M. Z. Slawin, J. D. Woollins and M. Arca, Eur. J. Inorg. Chem., 2012, 3577-3594.

9 B. Zheng, R. P. Sabatini, W.-F. Fu, M.-S. Eum, W. W. Brennessel, L. Wang, D. W. McCamant and R. Eisenberg, Proc. Natl. Acad. Sci. USA, 2015, 112, E3987-E3996.

10 J. P. Riehl and F. S. Richardson, Chem. Rev., 1986, 86, 1-16.

11 R. Carr, N. H. Evans and D. Parker, Chem. Soc. Rev., 2012, 41, 7673-7686.

12 G. Muller, Dalton Trans., 2009, 9692-9707.
13 C. Schaffner-Hamann, A. von Zelewsky, A. Barbieri, F. Barigelletti, G. Muller, J. P. Riehl and A. Neels, J. Am. Chem. Soc., 2004, 126, 9339-9348.

14 K. D. Oyler, F. J. Coughlin and S. Bernhard, J. Am. Chem. Soc., 2007, 129, 210-217.

15 (a) J. F. Kögel, S. Kusaka, R. Sakamoto, T. Iwashima, M. Tsuchiya, R. Toyoda, R. Matsuoka, T. Tsukamoto, J. Yuasa, Y. Kitagawa, T. Kawai and H. Nishihara, Angew. Chem. Int. Ed., 2016, 55, 13771381; (b) G.-Z. Lu, N. Su, Y. Li and Y.-X. Zheng, J. Organomet. Chem., 2017, 842, 39-46; (c) T. R. Schulte, J. J. Holstein, L. Krause, R. Michel, D. Stalke, E. Sakuda, K. Umakoshi, G. Longhi, S. Abbate, G. H. Clever, J. Am. Chem. Soc., 2017, 139, 6863-6866.

16 C. Shen, E. Anger, M. Srebro, N. Vanthuyne, K. K. Deol, T. D. Jefferson, Jr., G. Muller, J. A. G. Williams, L. Toupet, C. Roussel, J. Autschbach, R. Réau and J. Crassous, Chem. Sci., 2014, 5, 19151927.

17 N. Saleh, M. Srebro, T. Reynaldo, N. Vanthuyne, L. Toupet, V. Y. Chang, G. Muller, J. A. G. Williams, C. Roussel, J. Autschbach and J. Crassous, Chem. Commun., 2015, 51, 3754-3757.

18 Y. Shen and C.-F. Chen, Chem. Rev., 2012, 112, 1463-1535.

19 M. Gingras, Chem. Soc. Rev., 2013, 42, 968-1006.

20 T. Biet, K. Martin, J. Hankache, N. Hellou, A. Hauser, T. Bürgi, N. Vanthuyne, T. Aharon, M. Caricato, J. Crassous and N. Avarvari, Chem. Eur. J., 2017, 23, 437-446.

21 J. Bosson, G. M. Labrador, S. Pascal, F.-A. Miannay, O. Yushchenko, H. Li, L. Bouffier, N. Sojic, R. C. Tovar, G. Muller, D. Jacquemin, A. D. Laurent, B. Le Guennic, E. Vauthey and J. Lacour, Chem. Eur. J., 2016, 22, 18394-18403.

22 T. Biet, A. Fihey, T. Cauchy, N. Vanthuyne, C. Roussel, J. Crassous and N. Avarvari, Chem. Eur. J., 2013, 19, 13160-13167.

23 S. Grimme and S. D. Peyerimhoff, Chem. Phys., 1996, 204, 411-417.

24 B. W. Smucker, J. M. Hudson, M. A. Omary and K. R. Dunbar, Inorg. Chem., 2003, 42, 4714-4723.

25 J. A. Zuleta, J. M. Bevilacqua, D. M. Proserpio, P. D. Harvey and R. Eisenberg, Inorg. Chem., 1992, 31, 2396-2404. 